\title{
Development of a Simulator by Assimilating Survey Approach with Computational Theory for the Research of Organizational Activities
}

\author{
Yoshiki Nakamura ${ }^{\dagger}$ \\ College of Economic, Nihon University, Tokyo, Japan 101-8360, JAPAN \\ Tel: +81-3-3219-3447, E-mail: nakamura.yoshiki@nihon-u.ac.jp
}

Received, March 2, 2010; Revised, May 20, 2010; Accepted, June 9, 2010

\begin{abstract}
An enterprise must achieve both a sound organizational management and effective development of individual members while maintaining a balanced approach. Relative to this, there is a research field dubbed as Organizational Activation. However, there is a necessity to clarify various factors required for organizational activation and to propose a methodology for organization management. This study is an attempt to create a model from an organization-a University Seminar Class-and agents therein-the Students and the Teacher-with an assumed goal of advancing together toward the students' self-growth. The model is expressed on two dimensional planes with vectors through a computer. Vectors are composed of the growth, demand, member, hindrance and student vectors. These vectors provide data to the mathematical model for a simulation. Each agent provided the individual information from the questionnaire-conducted to 169 university students. From the analysis data and extrapolations, this study was able to craft a guideline for future seminar activity. It also examines the possibility of assimilation of the Questionnaire Approach and that of the Computational Organization Theory approach. Finally, this study discusses the future possibility of application of the Assimilated Method for research and development, and for project management.
\end{abstract}

Keywords: Organizational Activation, Vector Model, Simulation, Agent Model, Organizational Management

\section{INTRODUCTION}

Wittingly or unwittingly, Japanese enterprises are either victims of or direct contributors to the lingering economic recession happening in the country for the last two decades. However and even under these discouraging circumstances, private enterprises must create new products and various services with high added-values purposely to drive sales and profit growth. Hence, leaders of private firms need to efficiently manage their organization and operations. Likewise, various individuals affiliated with these private organizations are often requested to facilitate development of the former's professional knowledge and business skills. In Japanese business world, many company employees more often attempt to expand their expertise by their own volitions so as to contribute to the development of the firms they work. Private enterprises in Japan must frequently achieve effective organizational management while providing favorable environments for the individual employees to develop their respective professional knowledge. Companies are thus often required to keep the balance of these two necessities (Amabile, 1988). Relative to this point, there is a research field, known as "organizational activation", which investigates how to "activate" an organization (Oldham and Cummings, 1996. Huselid, 1995. Johnston, 1996). Briefly, "Organizational activation" refers to inducing researchers to exhibit their vitality and problem-solving skills over and above their capacity gained by being actually affiliated with the organization. It has often been pointed out that "speeding up of research and development (R\&D hereinafter)", "efficient communication among researchers" and "development of good human relations" are necessary to achieve organizational activation. Therefore, it becomes important to clarify factors required for organizational activation and propose a methodology for organization management.

There are two approaches that can be trodden in the course of researching organization management. The first approach is a research methodology using a questionnaire fielded among researchers and staffs of private enterprises. The results are analyzed to obtain the information needed for organization management (Barczak

$\uparrow$ : Corresponding Author 
and Wilemom, 2003; Huselid, 1995; Johnston, 1996; Johnston, 2000; Chen, 1999; Fisher, 2003; Wang, 2002.). For example, Amabile (1988), after examining factors influencing creativity and innovation in organization, devised a model to show the major phases in the organizational innovation processes and described the influence of organizational factors on individual creativity. Oldham and Cummings (1996) examined the independent and joint contributions of employees' creativity-relevant personal characteristics, and three characteristics of the organizational context: job complexity, supportive supervision, and controlling supervision. They examined 171 employees from two manufacturing facilities, and found that the most creative work was produced when the employees had appropriate creativity-relevant tasks, such as working on complex issues. Härenstam et al., (2004) also investigated organizational impact on working conditions and explored the associations between sectors, different types of organizational change, and working conditions. The research data were collected from managers and employees of 72 work sites. The resulting outputs were analyzed by cluster and showed that the variance in working conditions was significantly attributed to organizational level, whereas, organizational changes had more negative consequences in the public sector than in the private sector. The other approach is executed through regression analysis (Gerard and Latham, 2001; Jorgensen et al., 2007; Kor, 2003; Tan et al., 2003; Whitener, 2001) and that of the covariance structure (Schaubroeck, 1990; Eby and Dobbins, 1997. Seijts and Latham, 2001) of the result of questionnaires. These approaches are useful for understanding the researchers' knowledge and character. In addition, it is also important in understanding the researchers' notion of "what an organization should be", which is essential to organization management. However, this approach is accompanied by the following problems:

1) The approach is designed for analyzing questionnaires' results; thus, the analysis is limited to factfinding. By this reason, it necessitates further research to acquire the vital information to answer the question "what kind of management should be undertaken in the future."

2) The approach does not take into account the timetransition factor that determines whether which method completes a project faster.

3) The approach can only analyze the relationship between items through factor and covariant structure analyses; hence, needing the use of more realistic analyses, such as sensitivity analysis to come up with a more accurate and reliable results.

Computational Organizational Theory Approach is the second viable approach to organization management researches. This organization system analysis uses a computer and focus in understanding the agent activity through simulation. Agents' essential behaviors and principles involved in their activity, such as organization behavior, production, consumption, or sale activities, are highlighted (Battiston and Weisbuch, 2003; Bonabeau, 2002; Bruniaux and Ghith, 2003; Cederman, 2002; Putsch, 2003; Stauffer and Martins, 2003). In historical perspectives, various models were devised in relation to the said approach. Cohen et al. (1972) posited the "Garbage-can model" while Schelling (1971) proposed the "Segregation model." Epstein and Axtell (1996) used the "Sugar-space model" whereas Axelrod (1997) formed the "Social norm model." In recent years, various researchers delved in the field such as Lesser et al. (2000), Grosz and Kraus (1996), Tomikawa et al. (1995), among others.

More specifically, Inui and Sakurai (2001) adderssed a method of simulating asynchronous negotiation on resource transfer planning distributed among organizations. In analyzing resource transfer planning, they used a genetic algorithm for selecting appropriate combinations and discussing the results of the simulation. Parsons and Jennings (1998) proposed a framework, based on a system of argumentation, which permitted agents to negotiate acceptable ways of solving problems. Their framework provided a formal model of argumentbased reasoning and negotiation, while presenting details of a design philosophy that ensured a clear link between the formal model and its actual practice. They likewise described a case study of this relationship for a particular class of architects. Bonabeau (2002) adapted the agent simulation in four areas-flow simulation, organizational simulation, market simulation, and diffusion simulation. He argued that, when the agents exhibit complex behavior, including learning and adaptation, it was useful to summarize by using the agent-based management. Ligtenberg et al. (2004) explored the use of agents to simulate spatial scenarios based on modeling multi-actor decision making within a spatial planning process. They constructed a mathematical model and demonstrated how agent simulation can be used to simulate land use changes. Their outputs not only resulted to comparing a relative static set of criteria but also of a dynamic exchange of information and effects of hierarchical relations set with different objectives.

These approaches are helpful in proposing organization management systems because the approaches analyzed communication and behavior between agents and discuss methods for the activation of agents. Furthermore, since they can introduce the concept about future prospect and time consideration through the simulator, they are more convenient and effective than the first approach. However, these approaches are not without imperfections, thus:

1) The approaches necessitate the clarification of the perspective from which a project is being accomplished-a primary objective of organizational activity.

2) Most of the studies of this type compare the result of simulation with an actual event; hence, requiring the construction of a model because, precisely, it reflects an actual event.

3) Since projects sometimes fail to accomplish its ob- 
jectives, it is necessary to design a method that enables analysis of the causes of the failure and proposes solutions to prevent failures.

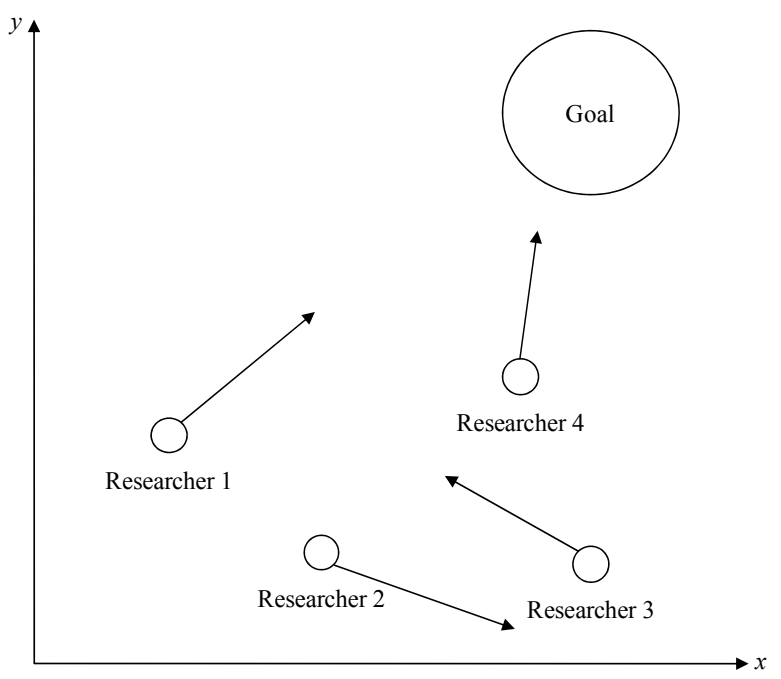

Figure 1. Two dimensional planes with vectors in preceding study.

To advance these two approaches, Nakamura and Tsuji (2004) (hereafter called preliminary study) attempted to create a model, wherein agents, assuming the role of R\&D researchers, were advancing together towards the same objective. To accomplish their objectives, they attempt to articulate their R\&D activities on two dimensional planes with vectors through a computer (Figure 1). The axis measures the distance between researchers and the goal.

The Vectors are composed of the strategy, interaction, basic and research vectors. This approach is useful to enable measurement of quantitative values of different activities, advancements, and reciprocal relationships in R\&D. They then used this model to set up a computerized simulation and examined the output for R\&D activities. The preliminary study demonstrated that "fitting research in line with the strategy of the organization is a factor in accelerating success by making the aim clear" and "presence of a good leader improved the outcome of the research." There are two major problems to be resolved. The first one is the lack of valid reason for setting parameters in a vector. In the preliminary study, direction and distance of research advances varied depending on how to set the vector; that is, the researchers' ability, expertise and knowledge is represented in the setting. However, the vector should primarily be set for individual researchers. The setting model should include the positional relationship to the goal and that the speed of achievement should be assessed using the vector. The second problem is the lack of factors for analyzing researchers' behavior toward achievement of the objective. In the preliminary study, the "strategy vector" was set to connect researchers with the objective because they factored that the researchers had to act in line with the strategy of the organization. However, not only the strategy vector but also the vectors for expertise and experiences must also have to be set. As a result, time required for achieving the objective must vary depending on the degree of agreement of these vectors with the researchers' actual expertise and experience, among others.

Thus, this preliminary study is conducted to solve two problems, namely: "introduction of information about individual researchers into their analysis" and "extraction of factors affecting achievement of the aim from the result." For this purpose, this preliminary study utilizes results obtained through a questionnaire for a Computational Organization Theory approach. The choice of the method is largely influence by the reason that questionnaire data contains information about the character and desire of individual researchers. This preliminary study can also clarify using this information about the relationship between their character/desire and achievement of the goal. Normally, this type of study should be conducted on the R\&D activity of enterprises. It is however difficult to fully examine the result of a simulation because sufficient data for a simulation cannot be obtained from a questionnaire distributed to enterprises due to the risk of information leakage (including personal information). Accordingly, this preliminary study was conducted as part of a seminar activity in the Nihon University. In Japanese universities, a seminar activity is where students are required to enroll in a small-sized seminartype of classes. Each seminar usually involves approximately ten to fifteen students. They will study the same topic, such as, business management studies, under the supervision of a professor. Each week, the students will present their homework and hold a discussion session.

The original theme of this preliminary study-"researchers aim for their goal"-was replaced with the theme "students' aim for self-growth through their seminar activity." In addition, the goal is set to "teacher's requirement for student growth" and is analyzed through its influence on the time required to arrive at the goal. A questionnaire used based on the previous work of Yahira (2008) that focused on the differences and commonality of being a part of a university seminar, a parttime job, and a group activity like a baseball team, a football team, among others. The questionnaire is composed of 31 items (Table 1) and was conducted to 169 university students. From the results yielded by the questionnaire, Yahira (2008) analyzed the different and common traits in the respondents' commitment to the organization they belong. Examples of the field of comparison are:

1) As to the comparison between the seminar and the part-time job, the seminar is stronger on the affective commitment (hereafter called AC) side while the part-time job is stronger on the calculative involvement (hereafter called CI) side.

2) As to the comparison between the part-time job and the group activity, the part-time job remains strong 
in the CI factors whereas the group activity is strong on the AC.

3) The seminar is profiled as a mix of the $\mathrm{AC}$ and the CI organization.

4) The part-time job is profiled purely as a CI organization, as characterized by not doing work more than the necessary and the primary motivation is the payment from the said work.

Where, affective commitment is as the relative strength of an individual's identification with, and involvement in a particular organization. Calculative involvement is the willingness of the individual to remain with a par- ticular system given an alternative job that provides slightly better outcomes for the individual (Lyman et al., 1974).

The following subjects are examined and considered through a model and a simulation that utilizes the results of the questionnaire:

1) Extraction of estrangement/asymmetry between teacher's requirement for students' growth and the students' sense of purpose.

2) Extraction of cause of 1).

3) Comparison of results obtained from different seminars.

Table 1. Question items.

\begin{tabular}{|c|c|}
\hline No & Question \\
\hline 1 & I may move to another seminar, if it teaches the same topic. \\
\hline 2 & I am happy being in this seminar. \\
\hline 3 & I feel to have made a mistake to enroll in this seminar. \\
\hline 4 & I will be able to tell my friends how wonderful my seminar is. \\
\hline 5 & I stay in the seminar because I feel it is my obligation. \\
\hline 6 & I am happy to find that my efforts have contributed to the growth of this seminar. \\
\hline 7 & Things important for the seminar are similarly critical for myself. \\
\hline 8 & I remain being a member of the seminar, primarily because others seem to look up on my group. \\
\hline 9 & I have given a top priority to various activities in this seminar. \\
\hline 10 & I always become uneasy whenever I think of leaving the seminar. \\
\hline 11 & I tryto do whatever I have to do for the sake of this seminar. \\
\hline 12 & Whenever a member of the seminar seems in trouble, I will help him as if it is a part of my own problem. \\
\hline 13 & I stay as a member of the seminar because it will benefit my job hunting. \\
\hline 14 & I do not want to sacrifice myself for the sake of this seminar. \\
\hline 15 & I do have a sense of belongingness of this seminar. \\
\hline 16 & As long as the seminar has something to offer, I will stay put in this group. \\
\hline 17 & This seminar has excellent interpersonal relationships. \\
\hline 18 & I stay in this seminar only to get credits. \\
\hline 19 & As soon as my job hunting is over, I will leave the seminar. \\
\hline 20 & I am extremely happy to have chosen this seminar, and not others. \\
\hline 21 & I always feel uneasy whenever I hear someone disrupting my seminar. \\
\hline 22 & Although the seminar will be a non-credit course, I will certainly remain as a member of the group. \\
\hline 23 & I have no regret even if the seminar will be dissolved after my graduation. \\
\hline 24 & I have never thought of quitting this seminar. \\
\hline 25 & It will take unordinary efforts to leave this seminar. \\
\hline 26 & If another appealing group exits, I will probably switch to that seminar. \\
\hline 27 & $\begin{array}{l}\text { If I move to another group, I may not receive different benefits that I have been getting from this current } \\
\text { seminar. }\end{array}$ \\
\hline 28 & I will choose the same seminar once again even if I have another chance. \\
\hline 29 & I think this seminar suits me. \\
\hline 30 & I feel grown up in this seminar. \\
\hline 31 & I have been satisfied with this seminar. \\
\hline
\end{tabular}


From these analysis and considerations, this study made a guideline for future seminar activity and examined the possibility of assimilating the Questionnaire approach and that of Computational Organization Theory approach. In addition, the study also discusses the future possibility of application of the assimilated method for organizational activity of R\&D and for project management.

\section{SEMINAR'S ACTIVITIES AND EXTRACTED VECTOR'S FACTORS}

Nihon University Department of Economics seminar's selection process is composed of two stages. First is the written examination and the second stage is the interview of students who expressed desire to join the seminar. The seminar professor however, has the responsibility to ultimately select who are those students that can join his/her seminar. For example, the herein author considers the desire of a student to deepen his/her expertise on the given field of specialty and/or who wants to study the importance of collaborative activity. On the other hand, the students' perspective possesses various motivations ranging, not only to the "content of the seminar" and "it is useful in the future", but also to "I want to grow up", "I want to enjoy the seminar activity" and "I want to increase the number of friends", among others. In the course of the seminar activity, various questions and problems arise both from the teachers and students. This study opines that these include:

1) Students' awareness of seminar activity is low because:

- Friendships take priority over study work

- The theme of the seminar is quite different from what the students were expecting

- Students participated in the seminar in order to obtain credits

2) Teacher's enthusiasm is not communicated to the students

3) Incompatible relationship between teachers and students

One of the reasons for these is the estrangement or asymmetry between the teacher's requirement for students' growth and the students' need for self-development. In other words, there are mal-appreciations and miscommunications between the teacher and the students especially on "what the teacher requires from the students" and "what the student requires from the teacher for the former's self-growth."

In Yahira's (2008) questionnaire results, the students' behaviors are classified into: 1) growth-relevant behaviors that change with transition of time and are related to the growth of students through classes, 2) request-relevant behaviors that are related to the demands made of students by the seminar, 3) member-relevant behaviors that are related to desire and expectation of students in relation to other members of the seminar, and 4) hindrance-relevant behaviors that are related to students' dissatisfaction with the seminar. These are because human's behavior are divided into a time, ego, mutual, and obstructed element. Thus, a model has to be constructed considering these items.

\subsection{The Vector's Model}

In this section, Table 2 classifies the student's behavior and expresses the same through a vector. Further, it introduces the preliminary problems which are "introduction of individual information" and "derivation with accomplishment items of a goal." To start with, there is a need to explain the process of forming a vector. Principal component analysis (Jobson, 1994) is carried out on each of the classified factors and calculated eigenvectors.

Afterwards, the vector of each factor is formed from the eigenvector of the primary principal component.

$$
\begin{aligned}
& \text { Component vector }= \\
& \text { eigenvector } 1 \times \text { question's answer } 1 \\
& + \text { eigenvector } 2 \times \text { question's answer } 2 \\
& +\cdots+\text { eigenvector } n \times \text { question's answer } n
\end{aligned}
$$

Where, $n$ is the number of questionnaires according to the classified element. The growth vector, member

\begin{tabular}{|c|c|c|c|}
\hline $\begin{array}{l}\text { Vector's } \\
\text { Item }\end{array}$ & $\begin{array}{l}\text { Question } \\
\text { number }\end{array}$ & $\begin{array}{c}\text { Vector's } \\
\text { Item }\end{array}$ & $\begin{array}{l}\text { Question } \\
\text { number }\end{array}$ \\
\hline \multirow{2}{*}{ Growth } & 2 & \multirow{6}{*}{ Member } & 6 \\
\hline & 30 & & 7 \\
\hline \multirow{11}{*}{ Request } & 4 & & 8 \\
\hline & 9 & & 12 \\
\hline & 11 & & 15 \\
\hline & 13 & & 17 \\
\hline & 20 & \multirow{4}{*}{ Hindrance } & 1 \\
\hline & 21 & & 14 \\
\hline & 22 & & 18 \\
\hline & 24 & & 19 \\
\hline & 27 & & \\
\hline & 28 & & \\
\hline & 31 & & \\
\hline
\end{tabular}
vector, and hindrance vector are adapted to this generalized vector.

Table 2. The students' behaviors classification.

On the other hand, to include in the demand vector possible demands of both teachers and students, the vector is expressed by adding the teacher's traction power, which refers to "teachers' student growth requirement."

\footnotetext{
Demand vector $=$ growth requirement 1 $\times$ eigenvector 1
} 


$$
\begin{gathered}
\times \text { question's answer } 1 \\
+\cdots+\text { growth requirement } n \\
\times \text { eigenvector } n \\
\quad \times \text { question's answer } n
\end{gathered}
$$

Thus, the goal may be more quickly achieved with an increase of agreement between the demand vector of teachers and that of students. The student vector is synthesized by integrating these vectors Figure 2. Therefore, the length of each vector reflects the questionnaire results of individual students. The positional relationship between individual students and the goal can be introduced into or extracted from the model. Now that the vector model had been introduced and set, the preliminary problems must now be introduced and will be explained in relation to each vector.

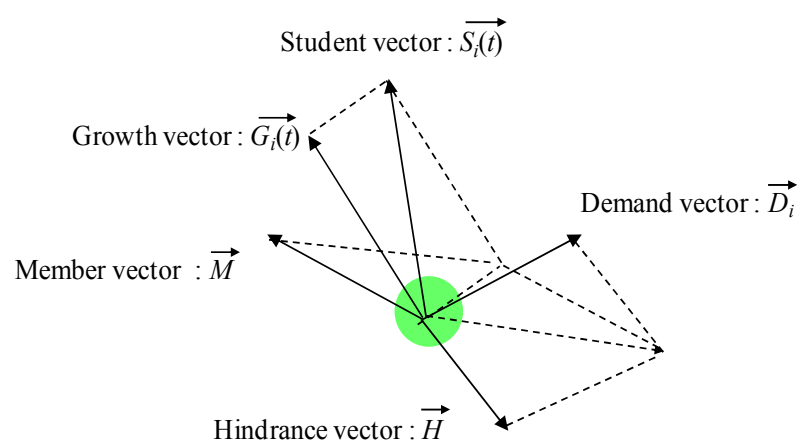

Figure 2. Vector model.

\subsection{The Growth Vector}

The growth vector changes according to the transition of time and is the factor which grows through the seminar activity. In the mathematical model;

$$
\overrightarrow{G_{i}(t)}=\sum_{j} E v g_{j} \times Q g_{i j} \times \cos \left(90^{\circ}-N r(t)\right) \text { for } \forall i
$$

Where,

$$
\begin{aligned}
& i \quad \text { Student } \\
& j \quad \text { Question item } \\
& \overrightarrow{G_{i}(t)} \text { Student } i \text { 's growth vector } \\
& E v g_{j} \text { Question item } j \text { 's eigenvector of the growth } \\
& \text { vector } \\
& Q g_{i j} \quad \text { Question item } j \text { 's, student } i \text { 's answer of the } \\
& N r(t)\left(0^{\circ} \leq N r(t) \leq 180^{\circ}\right) \\
& \text { Normal random numbers of every simulation } \\
& \text { term }
\end{aligned}
$$

In this vector, normal random numbers are generated every term, indicating that direction of the vector may change every term. That is, students are not only constantly heading toward the goal according to time but also change their pace and direction according to their environment and the passing of time. There is also a possibility that they advance in a completely different direction. To express this situation, normal random num- bers are multiplied to a generalized vector; as the generated random number is closer to $90^{\circ}$ the student more directly heads toward the goal, but as the generated number is closer to $0^{\circ}$ or $180^{\circ}$ the student takes a longer route to the goal Figure 3 .

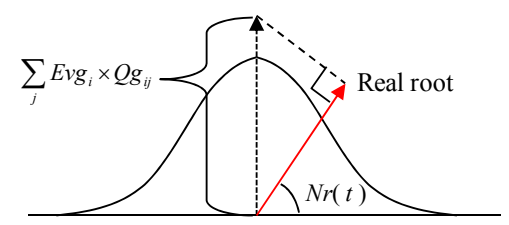

Figure 3. Direction of the growth vector.

\subsection{The Demand Vector}

The demand vector represents students' demands from the seminar activity. It includes "growth requirement," referring to teachers' student growth requirement. The growth requirement is the strength of the requirements from the students. In the mathematical model;

$$
\overrightarrow{D_{i}}=\sum_{j} E v d_{j} \times Q d_{i j} \times P u l_{j} \quad \text { for } \forall i
$$

Where

$\overrightarrow{D_{i}} \quad$ Student $i$ 's of demand vector

$E v d_{j}$ Question item j's eigenvector of the demand vector

Qdij Question item j's, student $i$ 's answer of the demand vector

$\mathrm{Pul}_{j}\left(1 \leq \mathrm{Pul}_{j} \leq 5\right)$

Question item $j$ 's growth requirement of the demand vector

These requirements and expectations come from the standpoint of an educator; any personal considerations such as the existence of personal relationship between the teacher and student are excluded. When this item is on a high value, it means that the teacher's requirement is high.

Same with a student's question falling on a high value, the demand vector must be also of a large value.

\subsection{The Member Vector}

The member vector represents the requests and expectations of students to other members of the seminar.

$$
\vec{M}=\frac{\sum_{i} \sum_{j} E v m_{j} \times Q m_{i j}}{i}
$$

Where,

$\vec{M} \quad$ Student member vector

$E v m_{j}$ Question item j's eigenvector of the member vector

$Q m_{i j}$ Question item $j$ 's, student $i$ 's answer of the member vector

In this study, the member vector is defined as the 
average total vector score of all the students in the seminar. Thus, it is the consensus of all members and the member vector is set irrespective of the direction of the goal. It does not also consider the difference in distance between the position of each member and the goal (Figure 4).

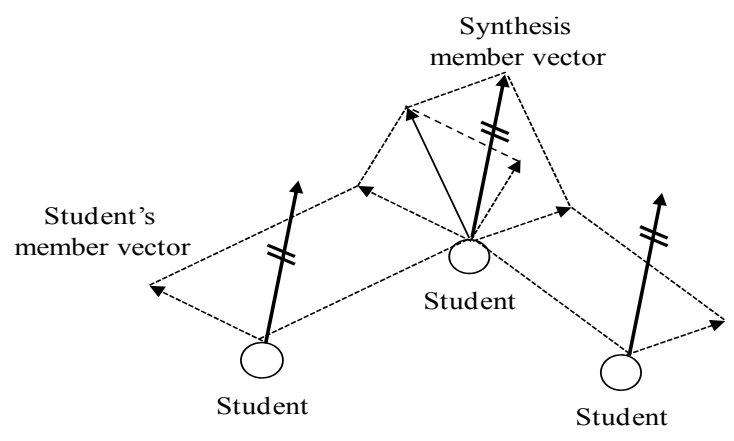

Figure 4. Example of the member vector.

\subsection{The Hindrance Vector}

The hindrance vector represents students' complaints regarding the seminar activity. This is the obstructive factor for the seminar activity.

$$
\overrightarrow{H_{i}}=\sum_{j} E v h_{j} \times Q h_{i j} \quad \text { for } \forall i
$$

Where,

$$
\begin{array}{ll}
\vec{H}_{i} & \text { Student } i \text { 's hindrance vector } \\
E v h_{j} & \begin{array}{l}
\text { Question item j's eigenvector of the hindrance } \\
\text { vector }
\end{array} \\
Q h_{i j} & \begin{array}{l}
\text { Question item } j \text { 's, student } i \text { 's answer of the hin- } \\
\text { drance vector }
\end{array}
\end{array}
$$

\subsection{The Student Vector and Learning Function}

The student vector is the integration of all vectors.

$$
\overrightarrow{S_{i}(t)}=\left\{\begin{array}{c}
\overrightarrow{G_{i}(t)}+\overrightarrow{D_{i}}+\vec{M}-\overrightarrow{H_{i}} \\
\quad \text { if } l(t-1) \leq l(t-2) \\
\overrightarrow{G_{i}(t)}+\overrightarrow{D_{i}}+\vec{M}-\overrightarrow{H_{i}}-\overrightarrow{S_{i}(t-1)} \\
\quad \text { if } l(t-1)>l(t-2)
\end{array} \text { for } \forall i\right.
$$

Where,

$\overrightarrow{S_{i}(t)}$ Student $i$ 's student vector in the $t$ term.

$l(t)$ Distance between student and target in the $t$ term

This vector is synthesized by adding up the growth, demand and member vectors, and subtracting the hindrance vector. Students must repeatedly confirm that they are heading towards the goal. If they take the wrong route, they are still heading towards the goal but are reflecting their past mistakes. This behavior is defined as "learning." For example, a mistake made can be derive if there exist a farther distance between the stu- dent and the goal as compared with distance $l(t-1)$ in preceding term and distance $l(t-2)$ in another preceding term. As a result, the student vector must add the synthesized vector in $\mathrm{t}$ term and the opposite direction of the student vector in $t-1$ term Figure 5 .

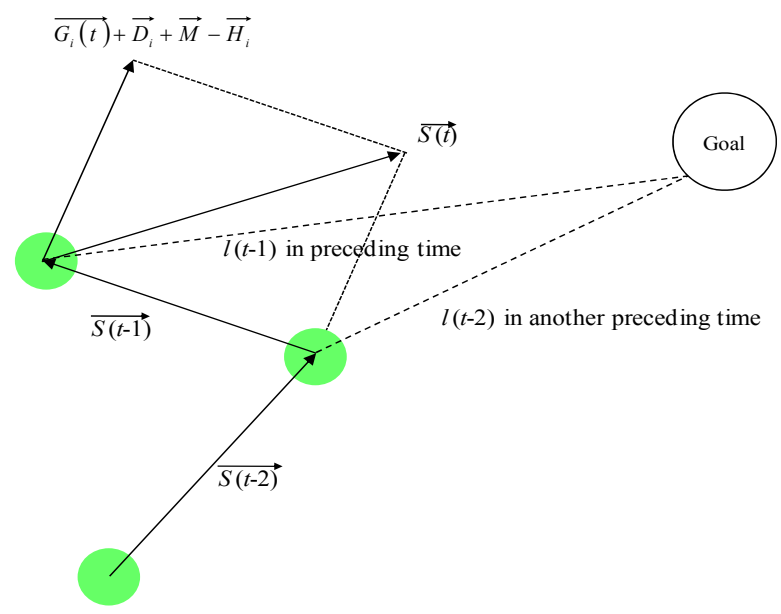

Figure 5. Learning behavior.

\subsection{The Goal}

The goal is the arrival point of achievement of selfgrowth of students through the seminar activity. The degree of difficulty in achieving this was divided into three classes. This simulation regards the arrival of even one member within range of the target as achieving the goal.

\section{THE SIMULATION'S RESULT AND CONSIDERATION}

The simulator is developed through the Visual Basic 2005 software inputting the concept as previously mentioned about the vector and the mathematical model.

Figure 6 is the screen shot during the introduction of the question's answer data, Figure 7 is the simulation screen shot while Figure 8 is the screen shot of the output data. "A" in the Fig 7 is goal difficulty, " $B$ " is the set growth requirement, " $\mathrm{C}$ " is the set simulation frequency, and "D" are the start and the end buttons. Before this study considered the simulation outputs, it examined first the Yahira's (2008) questions and the set answers. The questions elicit answers using a five-point Likert scale (1. Strongly disagree, 2. Disagree, 3. Neither agrees nor disagree, 4. Agree, 5. Strongly agree). The study targeted two seminar groups, herein labeled as seminar A and B. Seminar A is composed of 9 sophomore and 13 juniors students while Seminar B is comprised of 12 sophomore students. Table 3 is the output of the answers expressed in average and the T-test. A Ttest has to be conducted between the members of Seminar A's two kinds of students-that of sophomores and 
juniors,-as well as between seminar A and B themselves. The indication "*" means a $5 \%$ statistical significance while "**" means $1 \%$ statistical significance in one-side test. The growth requirement must be set by the seminar's teacher.

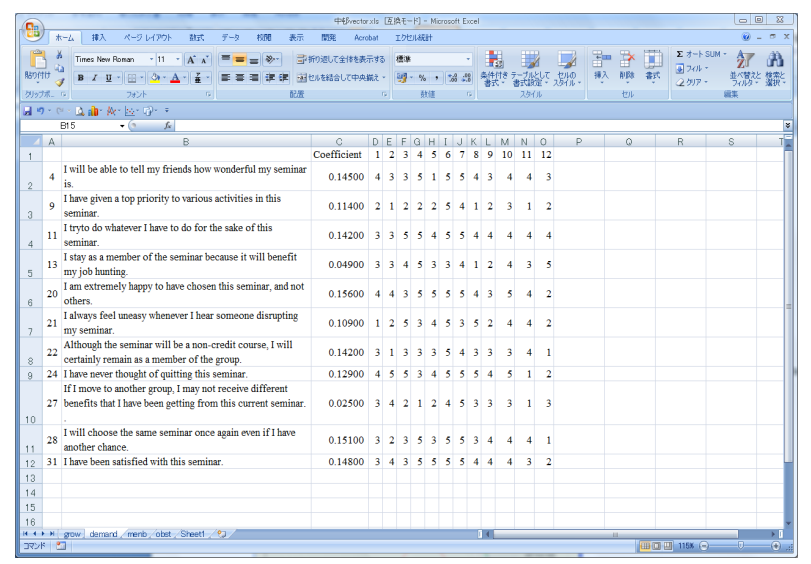

Figure 6. The question's answer data.

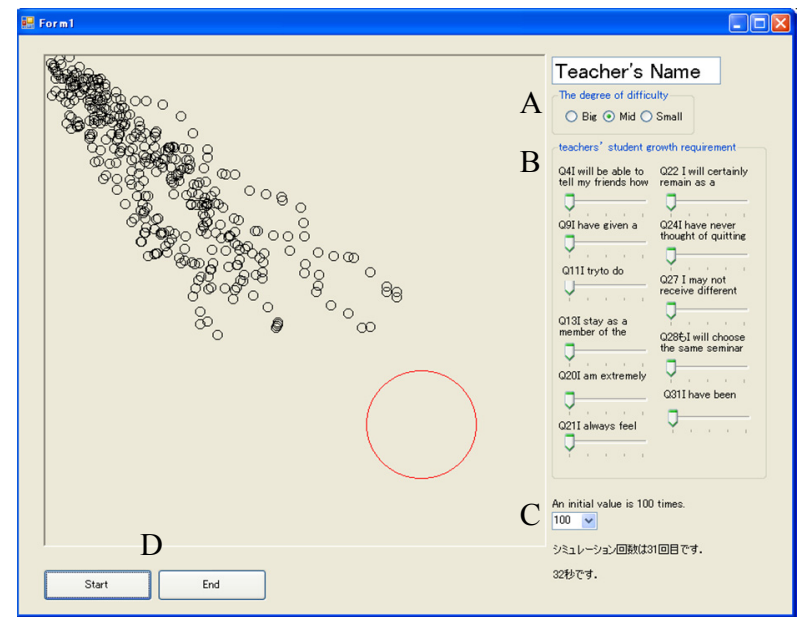

Figure 7. The simulation screen.

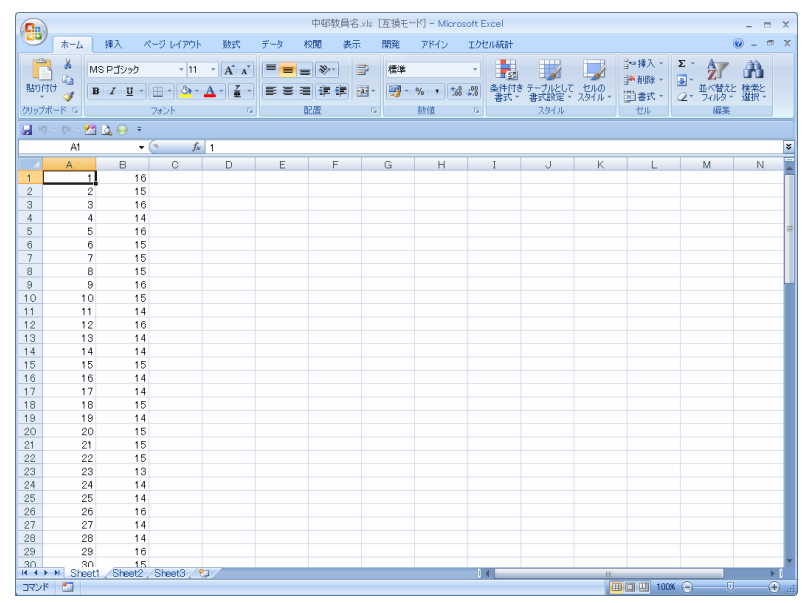

Figure 8. The screen of the output data.

Using these data, a simulation was conducted. Ta- ble 4 indicates the initial set data in each vector model. Numeric numbers reflect the outputs of the principal component analysis. Results of competition vary depending on the applied students $i$. Simulation produces the outputs as shown in Table 5 replicating therein each seminar's outputs on the average arriving time with a standard deviation. A T-test is conducted to all combination in Table 5 and is projected to obtain a $1 \%$ statistical significance.

At first, the results of Seminar A revealed that the mean arrival time of all students is longer than that of the students in each grade. The results indicate that, with an increase of the number of students, the vector becomes complicated, movement of students toward the goal becomes slower, and it takes more time for goals to be achieved. It therefore suggests the necessity for a small class size. Moreover, each grade of standard deviation is smaller than all students of Seminar A.

Table 3. Outputs of question answers.

\begin{tabular}{|c|c|c|c|c|c|c|c|c|}
\hline \multirow{2}{*}{$\begin{array}{l}\text { Question } \\
\text { item }\end{array}$} & \multirow{2}{*}{$\underset{\text { (All) }}{\text { Semina A }}$} & \multirow{2}{*}{$\begin{array}{c}\text { Semina A } \\
\text { (Soph) }\end{array}$} & \multirow{2}{*}{$\begin{array}{c}\text { Semina A } \\
\text { (Junior) }\end{array}$} & \multirow[t]{2}{*}{ Semina B } & \multicolumn{2}{|c|}{ T-test } & \multicolumn{2}{|c|}{$\begin{array}{l}\text { The growth } \\
\text { requirement }\end{array}$} \\
\hline & & & & & A & A-B & $\mathrm{A}$ & $\mathrm{B}$ \\
\hline 1 & 2.09 & 2.11 & 2.08 & 2.17 & & & & \\
\hline 2 & 3.95 & 4.33 & 3.69 & 3.75 & $*$ & & & \\
\hline 3 & 1.64 & 1.22 & 1.92 & 1.89 & $*$ & & & \\
\hline 4 & 3.27 & 3.67 & 3.00 & 3.67 & & & 3 & 4 \\
\hline 5 & 2.95 & 2.44 & 3.31 & 2.08 & $*$ & $*$ & & \\
\hline 6 & 4.41 & 4.22 & 4.54 & 4.08 & & & & \\
\hline 7 & 3.59 & 3.78 & 3.46 & 3.50 & & & & \\
\hline 8 & 1.45 & 1.44 & 1.46 & 1.33 & & & & \\
\hline 9 & 2.95 & 3.11 & 2.85 & 2.25 & & & 4 & 3 \\
\hline 10 & 3.32 & 3.00 & 3.54 & 2.33 & & $*$ & & \\
\hline 11 & 3.86 & 4.00 & 3.77 & 4.17 & & & 5 & 4 \\
\hline 12 & 3.68 & 4.00 & 3.46 & 3.42 & & & & \\
\hline 13 & 2.73 & 3.22 & 2.38 & 3.33 & & & 1 & 1 \\
\hline 14 & 3.73 & 3.78 & 3.69 & 2.42 & & $* *$ & & \\
\hline 15 & 4.09 & 4.11 & 4.08 & 4.08 & & & & \\
\hline 16 & 3.82 & 3.78 & 3.85 & 4.33 & & & & \\
\hline 17 & 3.77 & 3.78 & 3.77 & 4.25 & & $*$ & & \\
\hline 18 & 2.59 & 2.11 & 2.92 & 2.17 & $*$ & & & \\
\hline 19 & 2.05 & 1.78 & 2.23 & 1.67 & & & & \\
\hline 20 & 3.64 & 3.89 & 3.46 & 4.08 & & & 5 & 5 \\
\hline 21 & 3.27 & 3.33 & 3.23 & 3.33 & & & 3 & 1 \\
\hline 22 & 3.09 & 3.67 & 2.69 & 3.00 & $*$ & & 4 & 4 \\
\hline 23 & 2.27 & 2.11 & 2.38 & 1.83 & & & & \\
\hline 24 & 3.27 & 3.78 & 2.92 & 4.00 & & & 3 & 1 \\
\hline 25 & 2.86 & 2.56 & 3.08 & 3.42 & & & & \\
\hline 26 & 2.27 & 2.33 & 2.23 & 2.25 & & & & \\
\hline 27 & 2.86 & 2.44 & 3.15 & 2.83 & * & & 1 & 5 \\
\hline 28 & 3.09 & 3.00 & 3.15 & 3.50 & & & 4 & 2 \\
\hline 29 & 3.68 & 3.67 & 3.69 & 3.58 & & & & \\
\hline 30 & 3.91 & 4.11 & 3.77 & 3.75 & & & & \\
\hline 31 & 3.64 & 3.67 & 3.62 & 3.92 & & & 4 & 4 \\
\hline
\end{tabular}

In comparing the simulation result and that of the questionnaire, sophomore students have higher grade in the growth item " 2 . I am happy being in this seminar", and the demand fact " 22 . Although the seminar will be a non-credit course, I will certainly remain as a member of the group." In addition, the said group have lower grade in the hindrance item " 18 . I stay in this seminar only to get credits." This result suggests that the third grade students in Seminar A participate actively in the seminar activity, considering that the seminar activity gives them satisfaction regardless of the academic credit. 
A sensitivity analysis was also conducted in order to examine whether the mean arrival time differs depending on the teacher's traction power. The purpose of this analysis is the extraction of degree of estrangement/assymetry between teachers' student growth requirements and students' sense of purpose. In the three inquiry items of the questionnaire, namely-"13. I stay as a member of the seminar because it will benefit my job hunting", "21. I always feel uneasy whenever I hear someone disrupting my seminar" and "24. I have never thought of quitting this seminar"-teachers' traction power scored 1 in Seminar B. This indicates that students do not need that mindset for their activity. When a simulation was carried out and the score of teacher B was changed to 3 , the mean arrival time shortened (Seminar B (1-3) in Table 5).

Table 4. The initial set data.

\begin{tabular}{|c|c|}
\hline The Growth Vector & $\left(0.55 \times Q g_{i 2}+0.55 \times Q g_{i 30}\right) \times \cos \left(90^{\circ}-N r(t)\right)$ \\
\hline & $\begin{array}{l}0.15 \times Q d_{i 4}+0.11 \times Q d_{i 9}+0.14 \times Q d_{i 11}+0.05 \times Q d_{i 13} \\
+0.16 \times Q d_{i 20}+0.11 \times Q d_{i 21}+0.14 \times Q d_{i 22}+0.13 \times Q d_{i 24} \\
+0.03 \times Q d_{i 27}+0.15 \times Q d_{i 28}+0.15 \times Q d_{i 31}\end{array}$ \\
\hline The Member Vector & $\begin{array}{l}\left(0.21 \times Q m_{i 6}+0.23 \times Q m_{i 7}+0.05 \times Q m_{i 8}+0.23 \times Q m_{i 12}\right. \\
\left.+0.21 \times Q m_{i 15}+0.21 \times Q m_{i 17}\right) / i\end{array}$ \\
\hline 1 he Hindrance vector & $0.20 \times Q h_{i 1}+0.17 \times Q h_{i 4}+0.21 \times Q h_{i 18}+0.21 \times Q h_{i 19}$ \\
\hline
\end{tabular}

Table 5. The simulation outputs.

\begin{tabular}{|c|c|c|c|c|c|}
\hline & $\begin{array}{c}\text { Semina A } \\
\text { (All) }\end{array}$ & $\begin{array}{c}\text { Semina A } \\
\text { (Soph) }\end{array}$ & $\begin{array}{c}\text { Semina A } \\
\text { (Junior) }\end{array}$ & Semina B & $\begin{array}{c}\text { Semina B } \\
1 \sim 3\end{array}$ \\
\hline \hline $\begin{array}{c}\text { Mean of } \\
\text { arriving time }\end{array}$ & 17.89 & 14.05 & 15.18 & 15.08 & 13.76 \\
\hline SD & 0.93 & 0.85 & 0.80 & 0.78 & 0.60 \\
\hline
\end{tabular}

Therefore, the results recommend that teacher $\mathrm{B}$ can make estrangement smaller by running the seminar in the following way: teacher B should make the seminar activity helpful for job hunting, should improve the quality of education and service for students to prevent students from complaining, and should make students reluctant to withdraw from the seminar.

By these processes and results, the study was able to analyze the difference among the seminars, and gap of direction between teacher and students. More so, the above discussion reveals that the simulator used in this study can provide the very purpose of which the present study designed from the very inception: to create a simulator that will provide a guideline for future seminar activity.

\section{CONCLUSION}

Until more recently, Japanese enterprise seeks answer on how their organization can develop activation. While these questions can be confronted by many existing approaches as had been articulated in various previous researches, this study offered an alternative appro- ach by merging the Questionnaire Analysis Approach with Computational Organizational Theory Approach. This study went beyond theory and demonstrated that its constructed model can be actually applied. It simulated its model at Nihon University's seminars activities and from questionnaires' outputs. This study also provided vital information, as reflected by the results of the simulations, on the possible asymmetry in the sense of purpose between the teachers and the students, as well as the effectiveness of small-sized class education. Furthermore, this study indicated that the simulator can provide guides for seminar activities. Finally, the present study demonstrated the possibility of assimilating a Questionnaire Approach and a Computational Organization Theory Approach. Application of this simulator to a larger organization such as an enterprise requires, first, the conduct of a questionnaire survey to employees regarding organization activation and, second, the simulation of each project based on the result of the survey using the vector model. Thereafter, factors that influence the activity of each project can readily be examined and be compared to the activities of different projects using the analysis results. A number of problems remain yet to be resolved in these approaches. I will continue tackling with the issues in the future.

This study further recommends, as a form of further research on the subject matter, the following:

1) Introduction of a vector model for other various factors, including length of service (years), expertise, salary/incentive, contribution to the project, post, communication ability and enthusiasm of members.

2) Reliability improvement of the questionnaire, and

3) Introduction of self-assessment of members and assessment of members by managerial staff into a vector model.

\section{ACKNOWLEDGMENT}

This research was partially supported by Grant-inAid for Young Scientists (B), (19700646) in Japan, by Research Grant of Institute of Business Research in Nihon University and by Research Grant of Research Institute of Economic Science in Nihon University.

\section{REFERENCES}

Axelrod, R. (1997), The Complexity of Cooperation: Agent-Based Models of Competition and Collaboration, Princeton University Press.

Amabile, T. M. (1988), A Model of Creativity and Innovation in Organizations, Research in Organizational Behavior, 10, 123-167.

Barczak, G. and Wilemon, D. (2003), Team Member Experiences in New Product Development: Views from the Trenches, R\&D Management, 33, 463-479.

Battiston, S. and Weisbuch, G. (2003), Decision spread 
in the corporate board network, Advances in Complex Systems, 6, 631-644.

Bonabeau, E. (2002), Agent-based modeling: Methods and techniques for simulating human systems, PNAS, 99, 7280-7287.

Bruniaux, P. and Ghith, A. (2003), Modeling and parametric study of a fabric drape, Advances in Complex Systems, 62, 457-476.

Cederman, L. E. (2002), Endogenizing geopolitical boundaries with agent-based modeling, PNAS, 99, 7296-7303.

Chen, C. C., Ford, C. M., and Farris, G. F. (1999), Do rewards benefit the organization? the effects of reward types and the perceptions of diverse R\&D professionals, IEEE Transactions on Engineering Management, 46, 47-55.

Cohen, M. D., March, J. G., and Olsen, J. P. (1972), A garbage can model of organizational choice, Administrative Science Quarterly, 17, 1-25.

Eby, L. T. and Dobbins, G. H. (1997), Collectivistic orientation in teams: an individual and group-level analysis, Journal of Organizational Behavior, 18, 275-295.

Epstein, J. M. and Epstein, J. M. (1996), Growing Artificial Societies: Social Science from the Bottom Up (Complex Adaptive Systems), The MIT press.

Fisher, C. D. (2003), Why do lay people believe that satisfaction and performance are correlated? Possible sources of a commonsense theory, Journal of Organizational Behavior, 24, 753-777.

Geyskens, I., Steenkamp, J. E. M., Scheer, L. K., and Kumard, N. (1996), The effects of trust and interdependence on relationship commitment: A transAtlantic study, International Journal of Research in Marketing, 13, 303-317.

Härenstam, A., Bejerot, E., Leijon, O., Schéele, P., Waldenström, K. and The MOA Research Group. (2004), Multilevel analyses of organizational change and working conditions in public and private sector, $E \mathbf{E}$ ropean Journal of Work and Organizational Psychology, 13, 305-343.

Huselid, M. A. (1995), The Impact of Human Resource Management Practices on Turnover, Productivity, and Corporate Financial Performance, Academy of Management Journal, 38, 635-672.

Inui, T. and Sakurai, S. (2001), A basic Study on formation of collaborative behavior in a multi-agent pursuit game, IPSJ SIG Notes Contents Game Informatics, 5, 23-30.

Jobson, J. D. (1994), Applied Multivariate Data Analysis: Volume II: Categorical and Multivariate Methods, Springer.

Johnston, J. M. (2000), Behavior Analysis and the R\&D Paradigm, The Behavior Analyst, 23, 141-148.

Johnston, R. B. (1996), Planning or Organizing: the Im- plications of Theories of Activity for the Management of Operations, Omega, 24, 367-384.

Jorgensen, F., Laugen, B. T., and Boer H. (2007), Human Resource Management for Continuous Improvement, Creativity and Innovation Management, 16, 363-375.

Kor, Y. Y. (2003), Experience-Based Top Management Team Competence and Sustained Growth, Organization Science, 14, 707-719.

Ligtenberga, A., Wachowicza, M., Bregta, A. K., Beulensb, A. and Kettenis, D. L. (2004), A design and application of a multi-agent system for simulation of multi-actor spatial planning, Journal of Environmental Management, 72, 43-55.

Lesser, V., Horling, B., Raja, A. and Zhang, S. X. Q. (2000), BIG: An agent for resource-bounded information gathering and decision making, Artificial Intelligence, 118, 197-244.

Lyman, W. P., Ricfiard, M. S., Richard T. M. and Paul V. B. (1974), Organizational Commitment, Job Satisfacition and Turnover among Psychiatric Technicisans, Journal of Applied Psychology, 59, 603609.

Nakamura, Y. and Tsuji, M. (2004), An Analysis of the Method to Invigorate Organizations: From the View of Computational Organization Theory Approach in R\&D, Journal of Japan Industrial Management Association, 55, 1-8.

Oldham, G. R. and Cummings, A. (1996), Employee Creativity: Personal and Contextual Factors at Work, Academy of Management Journal, 39, 607-634.

Parsons, S., Sierra, C., and Jennings, N. R. (1998), Agents that reason and negotiate by arguing, Journal of Logic and Computation, 8, 261-292.

Putsch, F. (2003), Analysis and modeling of science collaboration networks, Advances in Complex Systems, 6, 477-485.

Schaubroeck, J. (1990), Investigating reciprocal causation in organizational behavior research, Journal of Organizational Behavior, 11, 17-28.

Schelling, T. C. (1971), Dynamic Models of Segregation, Journal of Mathematical Sociology, 1, 143-186.

Seijts, G. H. and Latham, G. P. (2001), The effect of distal learning, outcome, and proximal goals on a moderately complex task, Journal of Organizational Behavior, 22, 291-307.

Stauffer, D. and Martins, J. S. S. (2003), Asymmetry in the hierarchy model of bonabeau et al., Advances in Complex Systems, 6, 559-564.

Tan, H. H., Foo, M. D., Chong, C. L. and Ng, R. (2003), Situational and dispositional predictors of displays of positive emotions, Journal of Organizational Behavior, 24, 961-978.

Tomikawa, Y., Munetomo, M., Takai, Y., and Sato, Y. (1995), Emergence of Cooperative Strategies in a Multi Agent Game, IPSJ SIG Notes Artificial Intel- 
ligence, 102, 25-30.

Wang, C. W. and Horng, R. Y. (2002), The Effects of Creative Problem Solving Training on Creativity, Cognitive Type and R\&D Performance, $R \& D M a$ nagement, 32, 35-45.

Whitener, E. M. (2001), Do "high commitment" human resource practices affect employee commitment? A cross-level analysis using hierarchical linear modeling, Journal of Management, 27, 515-535.

Yahira, H. (2008), The difference and commonness of belonging consideration to the plural organizations -comparison analysis among a university seminar, a part-time job and a circle-, Graduation thesis of Nihon University (in Japanese). 